\title{
Guidelines
}

\section{Smoking Prevention and Cessation in the Africa and Middle East Region: A Consensus Draft Guideline for Healthcare Providers - Executive Summary}

\author{
Ahmed Yousif M. Ali ${ }^{\mathrm{a}}$ Tarek Safwat ${ }^{\mathrm{c}}$ Geoffrey Onyemelukwe ${ }^{\mathrm{d}}$ \\ Moh'd Amin Al Otaibi $^{b}$ Ashraf A. Amire Yousef N. Nawas ${ }^{f}$ Hichem Aouinag \\ Moulay Hicham Afif ${ }^{\text {h }}$ Chris T. Bolliger ${ }^{i}$

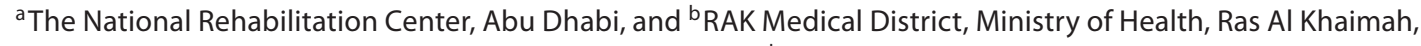

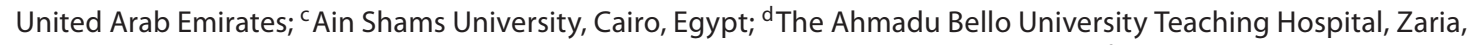 \\ Nigeria; ${ }^{\mathrm{e}}$ Family Medicine Center, International Medical Center, Jeddah, Saudi Arabia; ${ }^{\mathrm{f}}$ Private Practice, Amman, \\ Jordan; ${ }^{9}$ Charles Nicolle's Hospital, El Manar University, Tunis, Tunisia; ${ }^{\mathrm{h}}$ Respiratory Disease Department, 20th \\ August 1953 Hospital, Ibn Rochd University Hospital Center, Casablanca, Morocco; 'Division of Pulmonology, \\ Faculty of Health Sciences, University of Stellenbosch, Cape Town, South Africa
}

\section{Key Words}

Guidelines · Smoking cessation • Tobacco •

Pharmacotherapy - Nicotine replacement therapy •

Tobacco dependence

\begin{abstract}
Despite the abundance of scientific evidence confirming the health consequences of smoking and other forms of tobacco use, the tobacco epidemic remains an important public health problem and by 2030 it is predicted that more than $80 \%$ of tobacco deaths will be in developing countries. In Africa and the Middle East, many local factors contribute to the initiation and maintenance of tobacco use. Although efforts to reduce the mortality and morbidity associated with smoking and tobacco dependence are underway, there is a need for guidance on how to utilize appropriate tobacco control policies and psychology- and pharmacology-based therapies to counter tobacco dependence as recommended
\end{abstract}

\section{KARGER}

E-Mail karger@karger.ch www.karger.com/res
(C) 2012 S. Karger AG, Basel 0025-7931/12/0835-0423\$38.00/0

Karger

Open access

This is an Open Access article licensed under the terms of the Creative Commons Attribution- NonCommercial-NoDerivs 3.0 License (www.karger.com/OA-license), applicable to the online version of the article only. Distribution for non-commercial purposes only. by the Framework Convention on Tobacco Control (FCTC). A group of tobacco cessation experts from public health services and/or academic institutions in Africa and the Middle East participated in a series of four meetings held in Cairo, Cape Town, and Dubai between May 2008 and February 2011 to develop a draft guideline tailored to their region. This article provides the background to the development of this draft smoking cessation guideline and discusses how the recommendations can be implemented and progress monitored to promote both primary prevention and cessation of tobacco use within our countries. The draft guideline for Africa and the Middle East provides an important resource in combating the devastating effects of tobacco use in these regions which can be further localized through engagement with local stakeholders in the countries of the region.

Copyright $\odot 2012$ S. Karger AG, Basel
Prof. Chris T. Bolliger

Respiratory Research Unit, Faculty of Health Sciences

University of Stellenbosch, PO Box 19063

Cape Town, Tygerberg 7505 (South Africa)

Tel. +27 827132259 , E-Mail ctb@sun.ac.za 


\section{Introduction}

Tobacco kills a third to half of its users, with around 5 million tobacco-related deaths worldwide annually and a rising death toll projected to reach up to 1 billion throughout the 21st century [1-4]. Tobacco users die on average 10-15 years prematurely, and most smokers would like to quit but are unable to because of dependence $[2,5]$. Tobacco dependence as defined by the World Health Organization (WHO) International Classification of Diseases-10 (ICD-10) [6] is a chronic relapsing disease which is potentially treatable. Low- to middle-income countries in the developing world are already struggling with the epidemic of tobacco dependence and its complications, yet by 2030 it is predicted that more than $80 \%$ of tobacco deaths will be in these countries [2] (some 7 million deaths annually) [7], so averting further growth of this healthcare burden is vital.

Some countries within the developing world do not yet have the internal impetus to support development of their own national guidelines to promote smoking prevention and cessation [8], despite the mandate within the Framework Convention on Tobacco Control (FCTC) developed by the WHO, which states that 'each party shall develop and disseminate appropriate, comprehensive, and integrated guidelines based on scientific evidence and best practices, taking into account national circumstances and priorities, and shall take effective measures to promote cessation of tobacco use and adequate treatment for tobacco dependence' [9]. Regional guidelines may therefore be useful for such countries, as these provide a 'local' perspective (e.g. for cultural, geopolitical, and economic factors) while containing recommendations which are 'broad' enough in their applicability to allow neighboring countries to use these as a reference point when drawing up local strategies to promote smoking prevention and cessation.

\section{Developing a Regional Guideline for Smoking Prevention and Cessation}

The authors of this manuscript were initially identified as smoking cessation experts based on their knowledge and experience as part of a Pfizer-sponsored initiative to explore ways to tackle the tobacco epidemic in Africa and the Middle East. The nine clinicians work at public health services and/or academic institutions in eight different countries across Africa and the Middle East. At an initial meeting held in Cairo in May 2008, the authors explored tobacco cessation in Africa and the Middle East and committed themselves to developing a draft consensus smoking cessation guideline for their region. Over the following months, the authors defined an outline structure for the guideline chapters and then, working in groups, reviewed the relevant background literature for each chapter and developed a text summary of the key literature, including recommendations based on the evidence available in the literature, other national guidelines, and their own professional opinion. A further three meetings were held (the last of these in Dubai, United Arab Emirates, in February 2011) at which the authors presented their draft chapters and received detailed feedback from their peers within the group. Between these meetings, the authors continued to exchange information and ideas via e-mail and phone. The guideline document that evolved from this undertaking (online suppl. file; for all online suppl. material, see www.karger.com/doi/10.1159/000337726) is structured into the following chapters:

(1) Epidemiology of smoking in Africa and the Middle East

(2) Role of policies in controlling tobacco use

(3) Nonpharmacological interventions

(4) Pharmacological interventions

This flow ensures that the scale of the challenge is placed into perspective early on, so that the question of 'Why must we act?' is established clearly, then considering the question 'What can we do?' within the following three chapters. At a national level, the responsibility for public health issues surrounding tobacco use is shared by a variety of stakeholders, including general practitioners, specialists and healthcare workers, community and nongovernmental organizations, professional associations, and government departments. The selection of which approaches to use is based on the local priorities and resources available. The draft guideline aims to provide strategies which may be applied at national (i.e. policies), group (e.g. psychological/motivational support), and individual (e.g. psychological/motivational support and/or pharmacological support) levels (fig. 1).

\section{Local Factors Influencing the Epidemiology of the Tobacco Epidemic}

The countries of Africa and the Middle East face particular challenges in responding to the tobacco epidemic due to their young and growing populations combined with many local factors which contribute to the 
Fig. 1. Different levels of strategies covered by the draft smoking prevention and cessation guideline for the Africa and Middle East region.

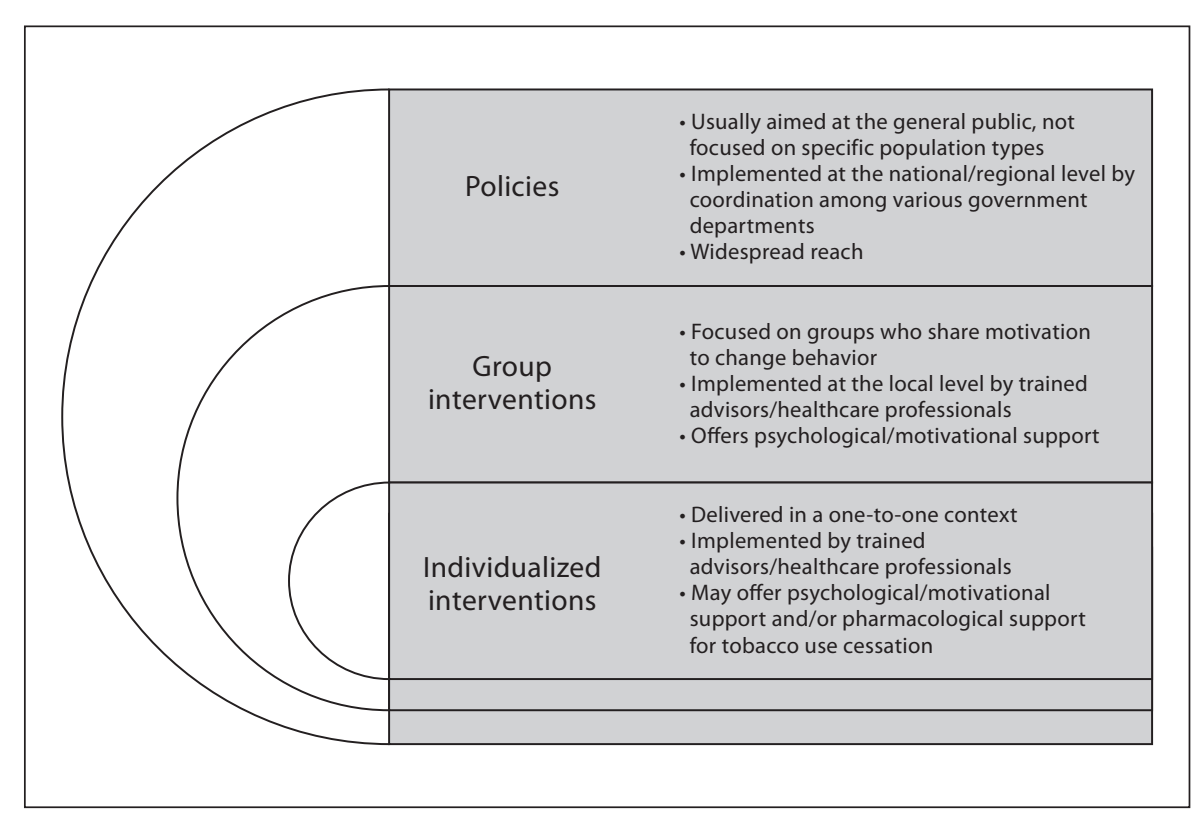

initiation and maintenance of tobacco use [10]. For example, the transnational tobacco companies which dominate the tobacco industry globally see growth potential in these markets as a means to offset declining consumption elsewhere [11-13]. These companies therefore invest heavily in consumer targeting operations and marketing strategies in Africa and the Middle East. Furthermore, in countries where the economy is tied to tobacco farming and export earnings from tobacco, such as Malawi, Zimbabwe, Tanzania, and Mozambique, the tobacco industry often wields more influence in opposing the introduction of tobacco control measures. In the Arab world, the male smoking prevalence has traditionally been high; however, the uptake of smoking by women is rising [14]. Waterpipe smoking is prevalent throughout the Middle East and North Africa region and is particularly common among high school students. Large numbers of young females are also taking up this habit, which may be due to a relative permissiveness of adult family members towards waterpipe use, despite a strong taboo against female cigarette smoking [15]. The widespread availability of smuggled cigarettes in many parts of Africa $[16,17]$ makes international brands more affordable to low-income consumers and to youth, thus stimulating consumption [1]. Consumption of smokeless tobacco, including dried snuff, chewed tobacco leaves, or dried tobacco balls (known as toombak in Sudan), is common among adults and youths in many parts of Africa [18-20].

Smoking Cessation and Prevention Guideline for Africa and the Middle East

\section{Ensuring Policies Are Suitable for Countries where Resources Are Limited}

To make sure that the public health policy recommendations within the new smoking cessation guidelines are as broadly applicable to the low- to middle-income countries within Africa and the Middle East as possible, costeffectiveness was considered. The policy recommendations focus on six policies which the World Bank identifies as highly cost-effective in reducing demand for tobacco products [21]:

(1) Higher taxes on cigarettes and other tobacco products

(2)Bans/restrictions on smoking in public and workplaces

(3) Comprehensive bans on advertising and promotion of all tobacco products, logos, and brand names

(4) Better consumer information

(5) Large, direct warning labels on cigarette boxes and other tobacco products

(6)Support programs for smoking cessation

Implementation of these six policies is required by countries which are signatories to the FCTC [9]. The recommendations within the draft guideline for Africa and the Middle East discuss ways to implement each of the policies locally, for example emphasizing the need to include smokeless tobacco and waterpipe tobacco products when applying higher taxation as a deterrent for tobacco use, to include public areas such as mosques and churches within smoking bans, and to ensure that warning la- 


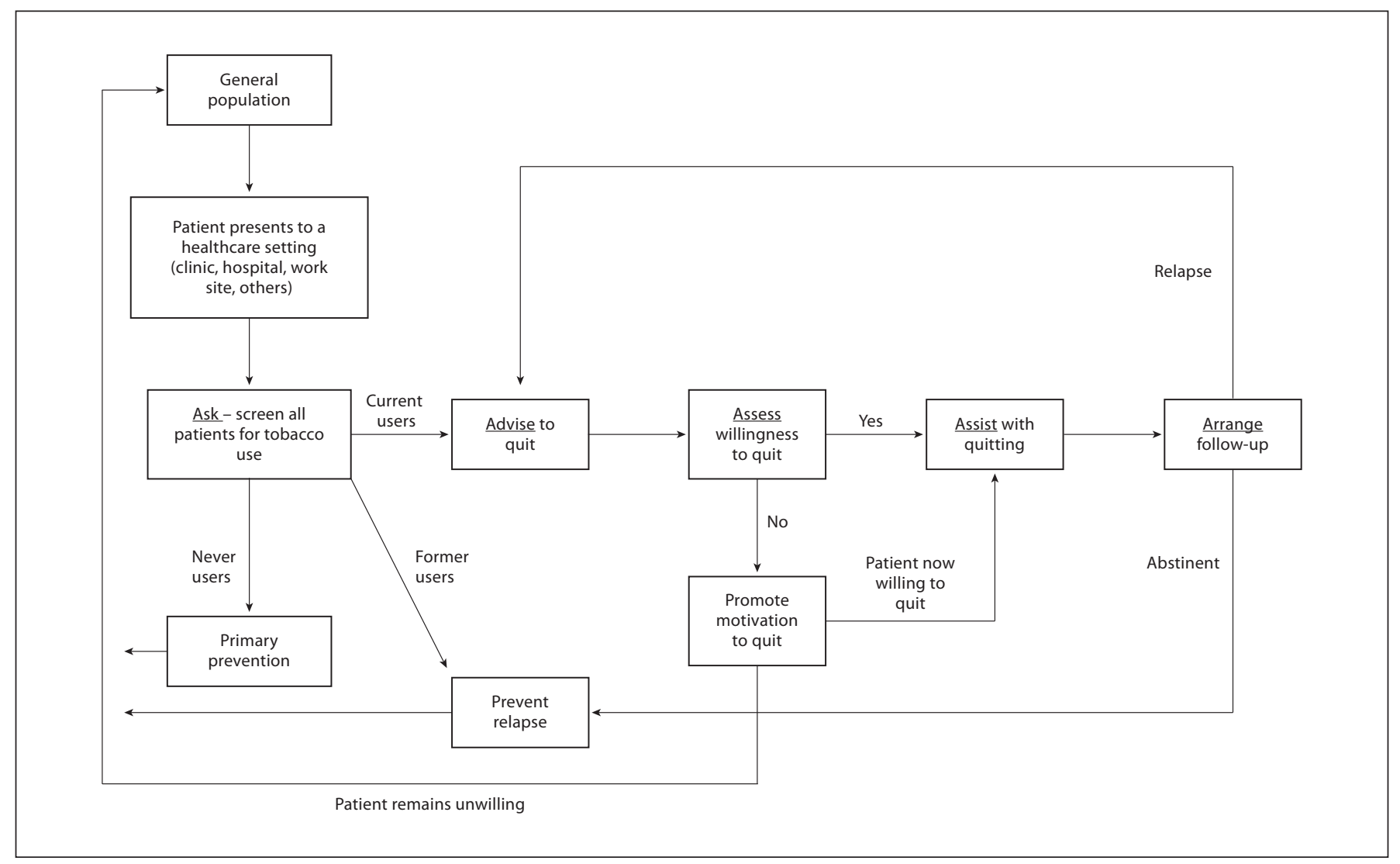

Fig. 2. The 5As model for treatment of tobacco use and dependence in primary care [22].

bels providing information on the dangers of tobacco use include visual images and text translated into any languages used by consumers.

\section{Group and Individualized Support for Treating Tobacco Dependence}

Support programs for smoking cessation consist of psychology- (behavioral) and pharmacology-based therapies to counter tobacco dependence, so the draft guidelines for Africa and the Middle East provide recommendations for the use of both strategies, which are aligned with those from current international guidelines [22, 23]. Accepting that tobacco dependence is a long-term illness is important for clinicians and healthcare professionals, as the majority of tobacco consumers will persist in use for many years and will typically cycle through multiple quit attempts, remission, and relapse. Tobacco dependence should therefore share the status of other chronic illnesses, with effective treatments given for as long as is necessary to achieve successful clinical outcomes [24]. Clinicians should use an individualized approach when choosing the most effective treatment strategy or strategies for each patient. Intensive interventions (e.g. combining individual or group counseling with medication, or prescribing the use of more than one type of medication) require more time and resources, so these may have a narrower reach but higher success rates [25].

Brief interventions (less than $10 \mathrm{~min}$ ) have also proven effective in encouraging tobacco users to recognize the impact of their habit on their health and to point them towards effective treatments that can help. These interventions can reach a wide population as only minimal time and resources are required for delivery [25]. Models for brief intervention in the primary care setting include the US Public Health Service's '5As' - Ask, Advise, Assess, Assist, and Arrange [22] (fig. 2) and the ABC (Ask about smoking status; give Brief advice to stop smoking to all smokers; and provide evidence-based Cessation 
Fig. 3. The $A B C$ algorithm for smoking cessation [26].

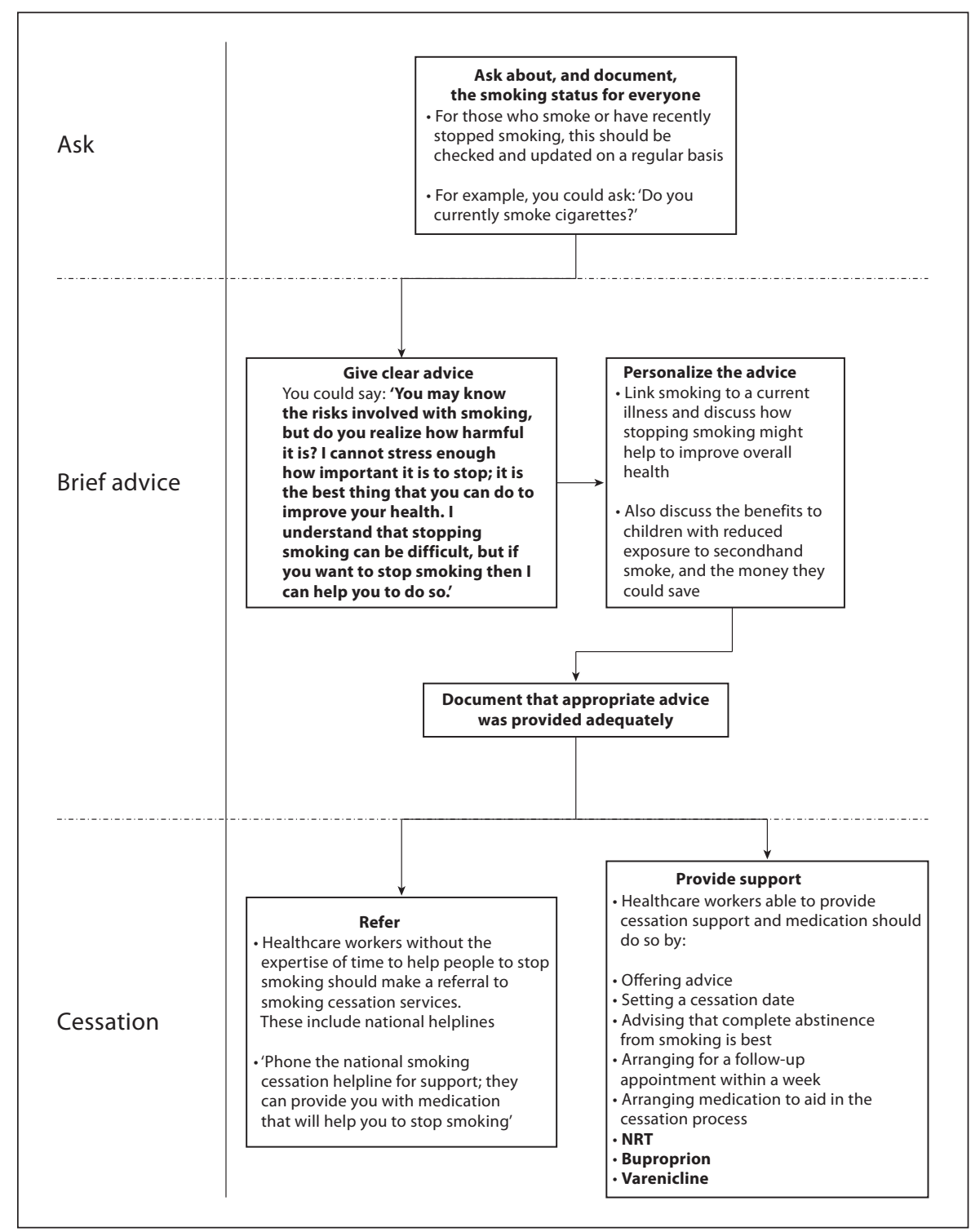

support for those who wish to stop smoking) algorithm from the New Zealand Ministry of Health 2007 guidelines [26] (fig. 3). In general, the 5As model is more widely known in the Africa and Middle East region, but both models are endorsed within our draft guideline as local preferences may vary.

Assessment of the severity of tobacco dependence will help to predict whether a smoker is likely to experience nicotine withdrawal upon smoking cessation, thus helping the therapist to select the most appropriate level of psychological and/or pharmacological support that will be needed. Validated tools such as the modified Fagerström test for cigarette dependence (FTCD) [27] or the
Lebanon Waterpipe Dependence Scale (LWDS-11) [28] can be used to measure tobacco dependence for both research and clinical purposes.

Central to all interventions is the need for willpower by the individual to overcome the symptoms of nicotine withdrawal and to succeed in changing their behavior. Ensuring that the health benefits of tobacco cessation are fully understood by the individual can help in this regard. These benefits begin within minutes of a smoker quitting and continue to increase steadily over time (fig. 4) [29].

Several first-line pharmacological therapies which increase the likelihood that a smoker will succeed in an attempt to quit are available. Nicotine replacement therapy 


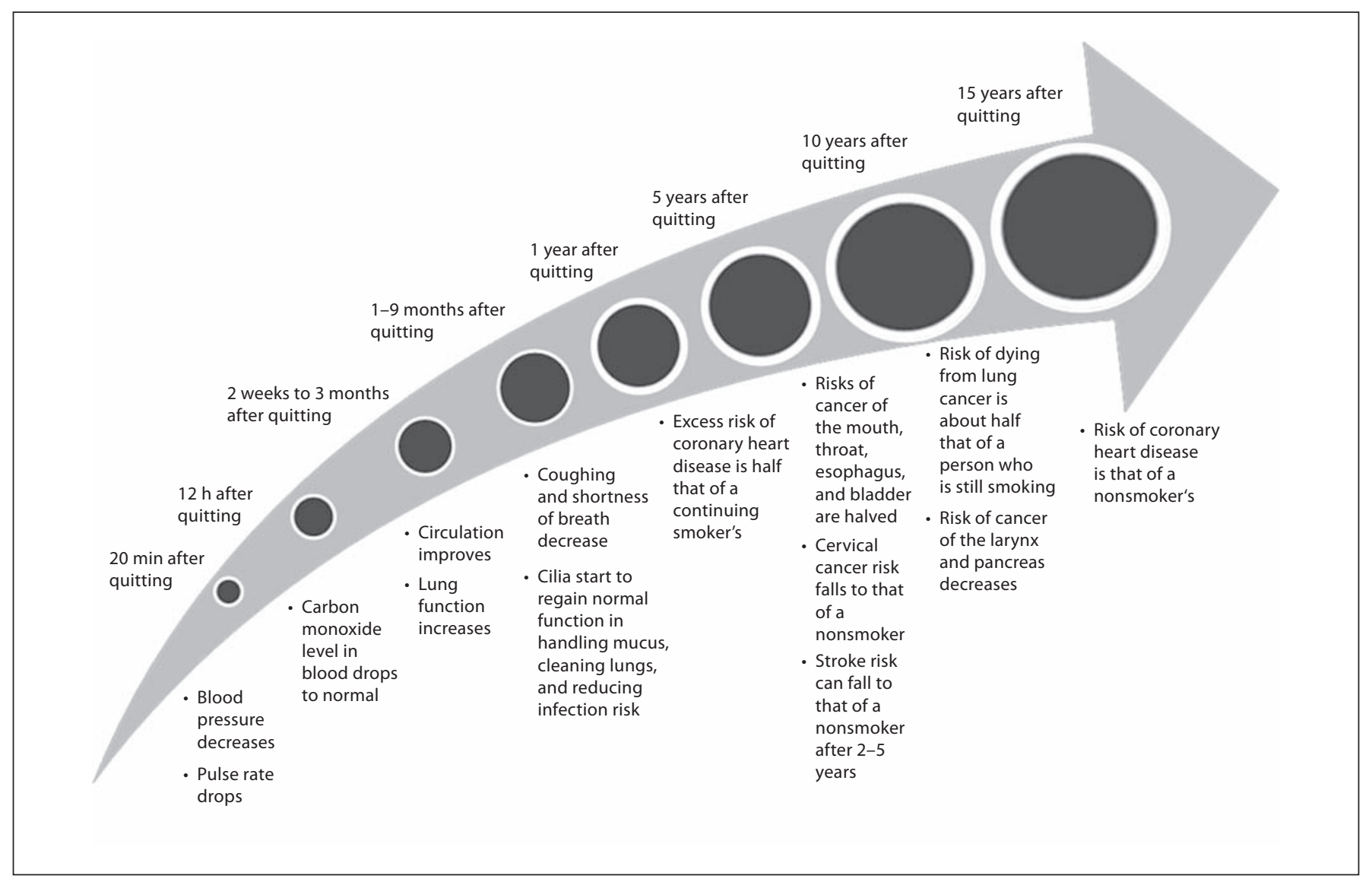

Fig. 4. The increased health benefits of tobacco cessation over time [29].

(NRT) (available in several formulations including patches, gum, lozenges, and inhalers), bupropion, and varenicline have all been proven to increase long-term abstinence from smoking when used as part of the cessation process $[22,30]$. Suggestions for the clinical use of these pharmacotherapies for smoking cessation are summarized in table 1 . The effectiveness and abstinence rates for various medications and medication combinations compared to placebo at 6 months post-quit are shown in table 2 .

As far as the different dosages and recommended durations for the different formulations within the NRT range are concerned, it is the consensus of the guideline members that, in clinical practice, all of these products are best used ad lib. For the duration of treatment, the maxim is: treat as long as required for cessation of tobacco dependence. There is evidence that higher NRT doses $[31,32]$, and longer NRT treatment duration [32, 33], can improve cessation outcomes, especially in high-dependency smokers.

\section{Limitations of This Work}

Throughout the guideline development, the authors recognized that the involvement of a pharmaceutical company could be perceived to present a potential conflict of interest. They therefore seek to clarify the following:

The views expressed within the draft guideline and this manuscript represent those of the authors, who have reviewed all information within these documents and have individually and collectively approved the content for publication; the authors' discussions and decisions on what information to include/exclude were not influenced by Pfizer at any stage.

The preparation of the content is fully in line with the Good Publication Practice 2 (GPP2) guidelines [34]. None of the authors received reimbursement for their role in the development, review, and approval of the draft guideline and this summary manuscript; support from Pfizer 
Table 1. Suggestions for the clinical use of pharmacotherapies for smoking cessation (adapted from US Public Health Service guidelines 2008) [22]

\begin{tabular}{|c|c|c|c|c|c|}
\hline Pharmacotherapy & $\begin{array}{l}\text { Precautions, } \\
\text { contraindications }\end{array}$ & Adverse effects & Dosage & Duration & Availability \\
\hline \multicolumn{6}{|l|}{ First-line } \\
\hline Nicotine inhaler & & $\begin{array}{l}\text { Local irritation of the mouth } \\
\text { and throat }\end{array}$ & $6-16$ cartridges/day & Up to 6 months & $\begin{array}{l}\text { Prescrip- } \\
\text { tion only }\end{array}$ \\
\hline Nicotine lozenge & & Nausea/heartburn & $\begin{array}{l}\text { If the time to the first cigarette smoked } \\
\text { each day is }>30 \text { min: } 2 \text { mg lozenge; if the } \\
\text { time to the first cigarette smoked each day } \\
\text { is } \leq 30 \mathrm{~min}: 4 \mathrm{mg} \text { lozenge. Between } 4 \text { and } \\
20 \text { lozenges/day }\end{array}$ & Up to 12 weeks & OTC only \\
\hline $\begin{array}{l}\text { Nicotine nasal } \\
\text { spray }\end{array}$ & & Nasal irritation & $8-40$ doses/day & $3-6$ months & $\begin{array}{l}\text { Prescrip- } \\
\text { tion only }\end{array}$ \\
\hline Nicotine patch & & Local skin reaction, insomnia & $\begin{array}{l}\text { Step down dosage from } 21 \mathrm{mg} / 24 \mathrm{~h} \text { for } \\
4 \text { weeks, then } 14 \mathrm{mg} / 24 \mathrm{~h} \text { for } 2 \text { weeks, } \\
\text { and then } 7 \mathrm{mg} / 24 \mathrm{~h} \text { for } 2 \text { weeks }\end{array}$ & Up to 8 weeks & $\begin{array}{l}\text { Prescrip- } \\
\text { tion and } \\
\text { OTC }\end{array}$ \\
\hline Varenicline & $\begin{array}{l}\text { Significant kidney } \\
\text { disease patients on } \\
\text { dialysis }\end{array}$ & $\begin{array}{l}\text { Nausea, abnormal (e.g. vivid, } \\
\text { unusual, or strange) dreams, } \\
\text { constipation, flatulence, and } \\
\text { vomiting }\end{array}$ & $\begin{array}{l}0.5 \mathrm{mg} / \text { day for } 3 \text { days, } 0.5 \mathrm{mg} \text { twice/day for } \\
4 \text { days, and then } 1 \mathrm{mg} \text { twice/day (begin } \\
\text { treatment } 1 \text { week pre-quit) }\end{array}$ & $3-6$ months & $\begin{array}{l}\text { Prescrip- } \\
\text { tion only }\end{array}$ \\
\hline
\end{tabular}

The information contained in this table is not comprehensive; please refer to the package inserts for additional information including safety information for your country. OTC $=$ Over the counter.

was limited to payment for authors' accommodation and travel expenses for attending the four guideline development meetings.

The tobacco epidemic has many causes and tackling these in Africa and the Middle East requires coordinated efforts involving all relevant stakeholders and deployment of the most cost-effective strategies available to target groups within society who already use tobacco or are at risk of starting (e.g. through public health policies aimed at the young) and individuals who are users but who will commit to changing their behavior (e.g. through counseling and/or pharmacological support for nicotine withdrawal symptoms). All recommendations within the guideline are accompanied by a summary of the available evidence base, and details of any adverse events associated with the use of each intervention are listed, thus aiming to ensure that the recommendations are balanced and free from bias.

Smoking Cessation and Prevention

Guideline for Africa and the Middle East
Lastly, the pharmaceutical industry is an important source of expertise and resources for healthcare systems within developing countries when addressing challenges such as infectious (e.g. HIV and TB), chronic (e.g. type 1 and 2 diabetes), and lifestyle-associated diseases (e.g. smoking-related cancer and cardiovascular disease). Engaging with pharmaceutical companies to take on public health initiatives which, due to lack of resources, may not otherwise be undertaken is a more pragmatic approach than excluding all such collaborations on principle, provided that the interaction is transparent and focused solely on addressing the healthcare challenge.

A further consideration is that the authors have endeavored to develop a draft guideline which is of benefit to a wide variety of stakeholders involved in tobacco use cessation. Due to the voluntary nature of the development and review process, it was not feasible to involve representatives of such groups, for example community 
Table 2. Effectiveness and abstinence rates for various medications and medication combinations compared to placebo at 6 months post-quit ( $\mathrm{n}=86$ studies) [22]

\begin{tabular}{|c|c|c|c|}
\hline Medication & $\begin{array}{l}\text { Number } \\
\text { of arms }\end{array}$ & $\begin{array}{l}\text { Estimated odds ratio } \\
\text { ( } 95 \% \text { confidence } \\
\text { interval) }\end{array}$ & $\begin{array}{l}\text { Estimated abstinence } \\
\text { rate }(95 \% \text { confidence } \\
\text { interval) }\end{array}$ \\
\hline Placebo & 80 & 1.0 & 13.8 \\
\hline \multicolumn{4}{|l|}{ Monotherapies } \\
\hline Varenicline (2 mg/day) & 5 & $3.1(2.5-3.8)$ & $33.2(28.9-37.8)$ \\
\hline Nicotine nasal spray & 4 & $2.3(1.7-3.0)$ & $26.7(21.5-32.7)$ \\
\hline \multicolumn{4}{|l|}{ High-dose nicotine patch $(>25 \mathrm{mg}$ ) (these included both standard and } \\
\hline long-term duration) & 4 & $2.3(1.7-3.0)$ & $26.5(21.3-32.5)$ \\
\hline Long-term nicotine gum (>14 weeks) & 6 & $2.2(1.5-3.2)$ & $26.1(19.7-33.6)$ \\
\hline Varenicline ( $1 \mathrm{mg} /$ day) & 3 & $2.1(1.5-3.0)$ & $25.4(19.6-32.2)$ \\
\hline Nicotine inhaler & 6 & $2.1(1.5-2.9)$ & $24.8(19.1-31.6)$ \\
\hline Clonidine & 3 & $2.1(1.2-3.7)$ & $25.0(15.7-37.3)$ \\
\hline Bupropion SR & 26 & $2.0(1.8-2.2)$ & $24.2(22.2-26.4)$ \\
\hline Nicotine patch (6-14 weeks) & 32 & $1.9(1.7-2.2)$ & $23.4(21.3-25.8)$ \\
\hline Long-term nicotine patch (>14 weeks) & 10 & $1.9(1.7-2.3)$ & $23.7(21.0-26.6)$ \\
\hline Nortriptyline & 5 & $1.8(1.3-2.6)$ & $22.5(16.8-29.4)$ \\
\hline Nicotine gum (6-14 weeks) & 15 & $1.5(1.2-1.7)$ & $19.0(16.5-21.9)$ \\
\hline \multicolumn{4}{|l|}{ Combination therapies } \\
\hline Patch (long-term; >14 weeks) + ad lib NRT (gum or spray) & 3 & $3.6(2.5-5.2)$ & $36.5(28.6-45.3)$ \\
\hline Patch + bupropion SR & 3 & $2.5(1.9-3.4)$ & $28.9(23.5-35.1)$ \\
\hline Patch + nortriptyline & 2 & $2.3(1.3-4.2)$ & $27.3(17.2-40.4)$ \\
\hline Patch + inhaler & 2 & $2.2(1.3-3.6)$ & $25.8(17.4-36.5)$ \\
\hline Patch + second-generation antidepressants (paroxetine, venlafaxine) & 3 & $2.0(1.2-3.4)$ & $24.3(16.1-35.0)$ \\
\hline \multicolumn{4}{|l|}{ Medications not shown to be effective } \\
\hline Selective serotonin re-uptake inhibitors (SSRIs) & 3 & $1.0(0.7-1.4)$ & $13.7(10.2-18.0)$ \\
\hline Naltrexone & 2 & $0.5(0.2-1.2)$ & $7.3(3.1-16.2)$ \\
\hline
\end{tabular}

The information contained in this table is not comprehensive; please refer to package inserts for additional information including safety information. Reproduced with permission from the 2008 US guidelines.

health workers or government health officials, so there is a need to engage with such stakeholders to confirm that the recommendations within the guideline are practical and appropriate. This validation of the guideline is planned as a next stage, once the draft recommendations are published as an open-access document and become available to a wider audience. Although the authors are all clinicians, harnessing the input from regional experts such as these allows neighboring countries to benefit from shared knowledge and others' experiences, providing a greater chance of identifying approaches which may be most suited to the local populations. A similar collaborative approach has been applied within Latin America, resulting in consensus guidelines for the prevention and treatment of tobacco dependence which have been endorsed by many healthcare organizations in countries throughout the region [35].

\section{Looking Ahead - How to Encourage Implementation of the Smoking Cessation Guidelines for Africa and the Middle East and Measure Progress?}

It is the authors' hope that the draft cessation guidelines for Africa and the Middle East will provide a userfriendly reference guide for stakeholders involved in primary prevention and cessation of tobacco use in our countries. It is planned to disseminate the guidelines document to public health organizations in these nations for their review which, after adaptation to local needs, could lead to endorsement in the form of a national guideline. Ultimately, translation of the content (initially developed in English) into additional languages and publication of printed copies of the guidelines as a booklet for healthcare professionals, smoking cessation counselors, and other professionals involved should also be undertaken. 
To quantify the implementation of tobacco control policies at the country level, the Tobacco Control Scale described by Joossens and Raw [36] could be applied to countries in Africa and the Middle East. This scale assigns a maximum score for each of the six policy measures discussed earlier and recommended by the WHO and World Bank [9, 21]. The scoring system was designed with the help of a panel of international tobacco control experts taking account of the relative effectiveness demonstrated for each of the six measures [36]. By scoring individual countries' performance in each of the six areas, each country's performance can be compared against the others. For example, if scores were calculated for ten countries in the Middle East in 2011, these countries could be reassessed 2 years later to determine whether progress had been made in implementing the key policies to reduce demand for tobacco products. This monitoring system has already been applied to 31 European countries and has identified countries where improvements have been made (for example, Slovenia improved its ranking by eight places in 2010, from 25th place among the 31 countries in 2007 to 17 th place in 2010 , following the introduction of successful smoke-free legislation in 2007) [37]. Surveying the current status of tobacco control activity in the countries of Africa and the Middle East using the Tobacco Control Scale and publication of results for these countries would providea useful benchmark against which future progress could be monitored and could serve to spur poorly performing countries to improve their ranking.

\section{Acknowledgements}

The authors wish to thank Dr. Guadalupe Ponciano for sharing key learnings and insights from the development of the Latin American Smoking Cessation guidelines document.

None of the authors received reimbursement for their role in the development, review, and approval of this document. The scientific expert panel meetings for the consensus guidelines document were funded by Pfizer. Editorial and medical writing support for the development of the manuscript and the full guidelines document was provided by Patrick Foley, PhD, of PHASE II International and was funded by Pfizer.

\section{Financial Disclosure and Conflicts of Interest}

All authors have completed the Unified Competing Interest form at www.icmje.org/coi_disclosure.pdf (available upon request from the corresponding author) and declare that accommodation costs for all authors attending the guideline meetings were paid directly by Pfizer; H.A. and C.T.B. were reimbursed by Pfizer for travel expenses incurred when attending the guideline meetings; A.Y.M.A. has received payments from Pfizer for presentations on smoking cessation; Y.N.N. and C.T.B. have received payments from Pfizer for delivering lectures and have also received consulting fees from Pfizer, and the authors have no nonfinancial interests that may be relevant to the submitted work.

\section{References}

1 Shafey O, Eriksen M, Ross H, Mackay J: The Tobacco Atlas, ed 3. Georgia, American Cancer Society, 2009. http://www.cancer. org/aboutus/globalhealth/cancerandtobaccocontrolresources/the-tobacco-atlas-3rdedition (accessed December 12, 2011).

2 World Health Organization: Report on the Global Tobacco Epidemic, 2008: the MPOWER Package. Geneva, WHO, 2008. http:// whqlibdoc.who.int/publications/2008/ 9789241596282_eng.pdf (accessed December 12, 2011).

3 Adcock IM, Caramori G, Barnes PJ: Chronic obstructive pulmonary disease and lung cancer: new molecular insights. Respiration 2011;81:265-284.

-4 Koczulla AR, Noeske S, Herr C, Jörres RA, Römmelt H, Vogelmeier C, Bals R: Acute and chronic effects of smoking on inflammation markers in exhaled breath condensate in current smokers. Respiration 2010;79:61-67.
5 Doll R, Peto R, Boreham J, Sutherland I: Mortality in relation to smoking: 50 years' observations on male British doctors. BMJ 2004;328:1519.

6 World Health Organization: International Statistical Classification of Diseases and Related Health Problems 10th Revision, Version for 2007. http://apps.who.int/classifications/apps/icd/icd10online/ (accessed December 12, 2011).

7 Abdullah AS, Husten CG: Promotion of smoking cessation in developing countries: a framework for urgent public health interventions. Thorax 2004;59:623-630.

8 Maziak W, Eissenberg T, Klesges RC, Keil U, Ward KD: Adapting smoking cessation interventions for developing countries: a model for the Middle East. Int J Tuberc Lung Dis 2004;8:403-413.
9 World Health Organization: WHO Framework Convention on Tobacco Control. Geneva, World Health Organization, 2003. http://www.who.int/fctc/en/ (accessed December 12, 2011).

10 Hawari F, Obeidat N, Beano H, Dawahrah S, Al-Rimawi D, Ghonimat I: Smoking abstinence rates and reasons for the failure to quit smoking in cancer patients in Jordan. Respiration 2012;83:233-238.

11 Nakkash R, Lee K: The tobacco industry's thwarting of marketing restrictions and health warnings in Lebanon. Tob Control 2009; 18:310-316

12 Mamudu HM, Hammond R, Glantz SA: Project Cerberus: tobacco industry strategy to create an alternative to the Framework Convention on Tobacco Control. Am J Public Health 2008;98:1630-1642. 
13 Patel P, Collin J, Gilmore AB: 'The law was actually drafted by us but the Government is to be congratulated on its wise actions': British American Tobacco and public policy in Kenya. Tob Control 2007;16:1-8.

14 Shafey O: Health issues in the Arab American community: global epidemiology and health hazards of tobacco use - Arab world patterns. Ethn Dis 2007;17(2 suppl 3):S3-13S3-15.

15 Maziak W: Commentary: the waterpipe - a global epidemic or a passing fad. Int J Epidemiol 2010;39:857-859.

- 16 LeGresley E, Lee K, Muggli ME, Patel P, Collin J, Hurt RD: British American Tobacco and the 'insidious impact of illicit trade' in cigarettes across Africa. Tob Control 2008; 17:339-346.

17 Titeca K, Joossens L, Raw M: Blood cigarettes: cigarette smuggling and war economies in central and eastern Africa. Tob Control 2011;20:226-232.

18 Ayo-Yusuf OA, van Wyk C, van Wyk CW, de Wet I: Smokeless tobacco products on the South African market do not inhibit oral bacterial flora: a pilot study. South Afr J Epidemiol Infect 2005;20:136-139.

-19 Idris AM, Ibrahim YE, Warnakulasuriya KA, Cooper DJ, Johnson NW, Nilsen R: Toombak use and cigarette smoking in the Sudan: estimates of prevalence in the Nile state. Prev Med 1998;27:597-603.

20 Rudatsikira E, Muula AS, Siziya S: Current use of smokeless tobacco among adolescents in the Republic of Congo. BMC Public Health 2010;10:16.

21 World Bank: Tobacco control: at a glance. 2003. http://siteresources.worldbank.org/ INTPHAAG/Resources/AAGTobacControlEngv46-03.pdf (accessed December 12, 2011).
22 Fiore MC, Jaén CR, Baker TB, et al: Treating Tobacco Use and Dependence: 2008 Update. Clinical Practice Guideline. Rockville, Department of Health and Human Services, 2008. http://www.ncbi.nlm.nih.gov/books/ NBK12193/ (accessed December 12, 2011).

23 National Institute for Health and Clinical Excellence: Brief interventions and referral for smoking cessation in primary care and other settings. 2006. http://www.nice.org. uk/nicemedia/live/11375/31864/31864.pdf (accessed December 12, 2011).

24 Steinberg MB, Schmelzer AC, Richardson DL, Foulds J: The case for treating tobacco dependence as a chronic disease. Ann Intern Med 2008;148:554-556.

25 Mottillo S, Filion KB, Bélisle P, Joseph L, Gervais A, O'Loughlin J, Paradis G, Pihl R, Pilote L, Rinfret S, Tremblay M, Eisenberg MJ: Behavioural interventions for smoking cessation: a meta-analysis of randomized controlled trials. Eur Heart J 2009;30:718730 .

26 Department of Health, New Zealand: New Zealand Smoking Cessation Guidelines. 2007. http://www.moh.govt.nz/moh.nsf/indexmh/nz-smoking-cessation-guidelines (accessed December 2011).

27 Fagerström KO: Determinants of tobacco use and renaming the FTND to the Fagerström Test for Cigarette Dependence. Nicotine Tob Res 2012;14:75-78.

28 Salameh P, Waked M, Aoun Z: Waterpipe smoking: construction and validation of the Lebanon Waterpipe Dependence Scale (LWDS-11). Nicotine Tob Res 2008;10:149158.

29 American Cancer Society (ACS): Guide to quitting smoking. 2011. http://www.cancer. org/acs/groups/cid/documents/webcontent/ 002971-pdf.pdf (accessed August 18, 2011).

30 Henningfield JE, Fant RV, Buchhalter AR, Stitzer ML: Pharmacotherapy for nicotine dependence. CA Cancer J Clin 2005;55:281299.
1 Tønnesen P, Paoletti P, Gustavsson G, Russell MA, Saracci R, Gulsvik A, Rijcken B, Sawe U: Higher dosage nicotine patches increase one-year smoking cessation rates: results from the European CEASE trial. Collaborative European Anti-Smoking Evaluation. European Respiratory Society. Eur Respir J 1999;13:238-246.

32 Stead LF, Perera R, Bullen C, Mant D, Lancaster T: Nicotine replacement therapy for smoking cessation. Cochrane Database Syst Rev 2008;1:CD000146.

33 Shiffman S, Khayrallah M, Nowak R: Efficacy of the nicotine patch for relief of craving and withdrawal 7-10 weeks after cessation. Nicotine Tob Res 2000;2:371-378.

34 Graf C, Battisti WP, Bridges D, BruceWinkler V, Conaty JM, Ellison JM, Field EA, Gurr JA, Marx ME, Patel M, Sanes-Miller C, Yarker YE, International Society for Medical Publication Professionals: Research Methods and Reporting: Good publication practice for communicating company sponsored medical research - the GPP2 guidelines. BMJ 2009;339:b4330.

35 Coalición Latinoamericana de Profesionales de la Salud para el Tratamiento de la Dependencia al Tabaco: Actualizaciones Latinoamericanas sobre prevención y tratamiento del tabaquismo. 2010. http://www.asat.org. ar/novedades.php (accessed December 12, 2011).

36 Joossens L, Raw M: The Tobacco Control Scale: a new scale to measure country activity. Tob Control 2006; 15:247-253.

37 Joossens L, Raw M: The Tobacco Control Scale in Europe. Brussels, Association of European Cancer Leagues, 2010. 